This item was submitted to Loughborough's Research Repository by the author.

Items in Figshare are protected by copyright, with all rights reserved, unless otherwise indicated.

\title{
Examining the strategic alignment and implementation success of a KMS: A subculture-based multilevel analysis
}

PLEASE CITE THE PUBLISHED VERSION

http://dx.doi.org/10.1287/isre.1080.0214

PUBLISHER

(C) INFORMS

VERSION

VoR (Version of Record)

LICENCE

CC BY-NC-ND 4.0

\section{REPOSITORY RECORD}

Ravishankar, M.N., Shan L. Pan, and Dorothy E. Leidner. 2019. "Examining the Strategic Alignment and Implementation Success of a KMS: A Subculture-based Multilevel Analysis". figshare.

https://hdl.handle.net/2134/14662. 
This item was submitted to Loughborough's Institutional Repository (https://dspace.lboro.ac.uk/) by the author and is made available under the following Creative Commons Licence conditions.

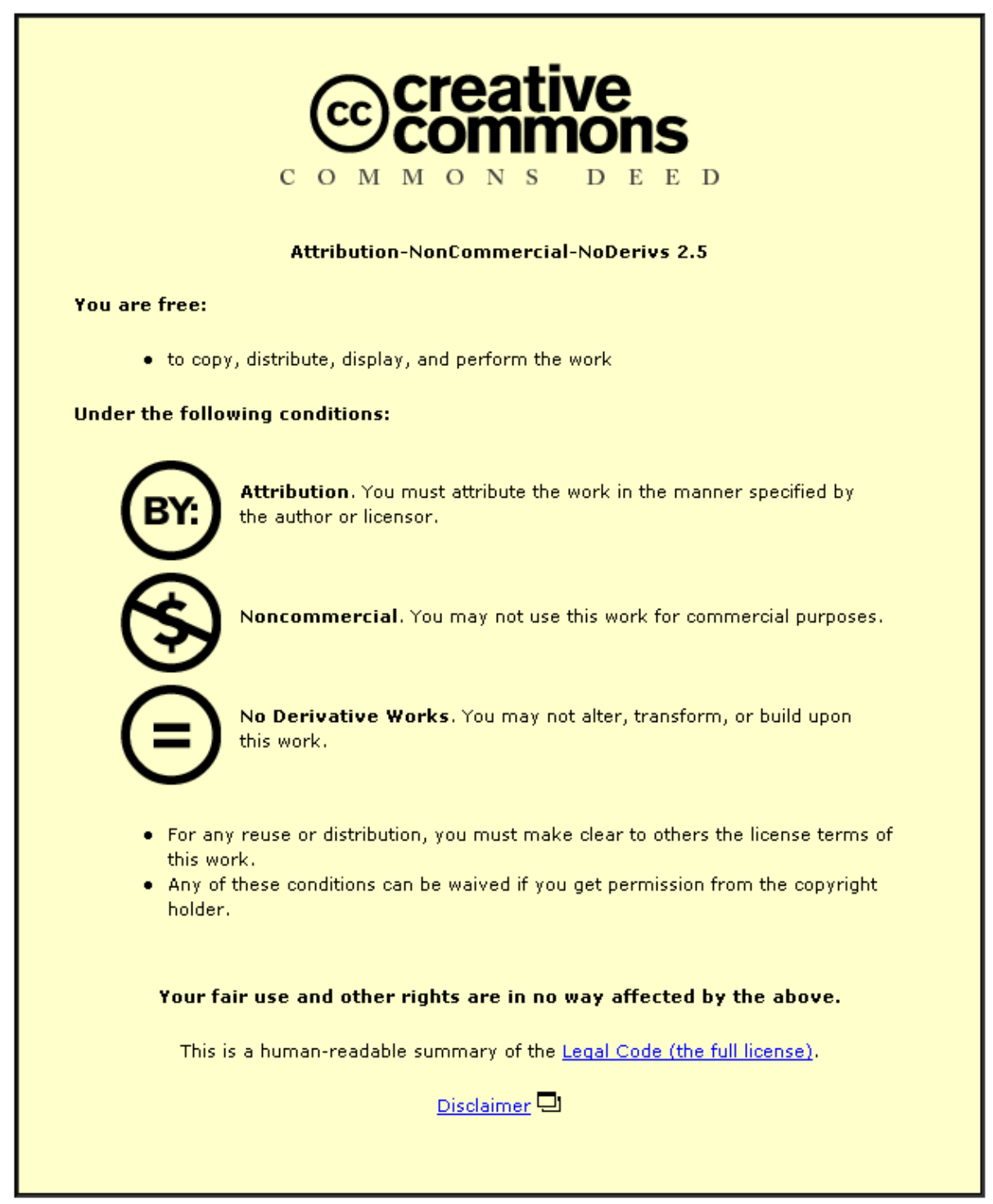

For the full text of this licence, please go to: http://creativecommons.org/licenses/by-nc-nd/2.5/ 


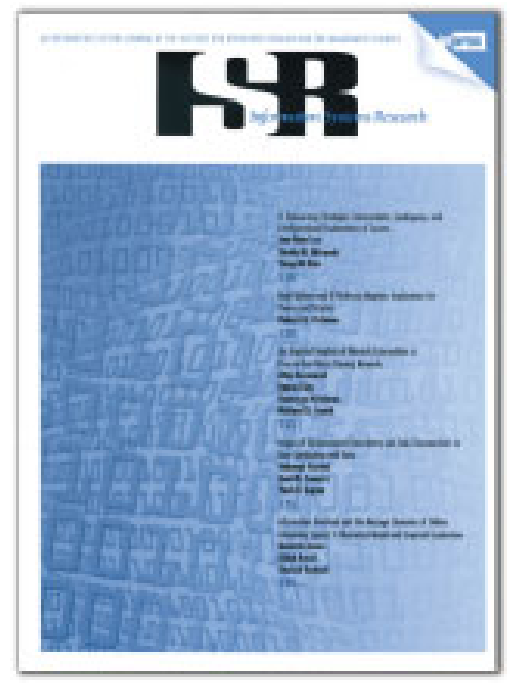

\section{Information Systems Research}

Publication details, including instructions for authors and subscription information: http:// pubsonline.informs. org

\section{Examining the Strategic Alignment and Implementation Success of a KMS: A Subculture-Based Multilevel Analysis}

M. N. Ravishankar, Shan L. Pan, Dorothy E. Leidner,

\section{To cite this article:}

M. N. Ravishankar, Shan L. Pan, Dorothy E. Leidner, (2011) Examining the Strategic Alignment and Implementation Success of a KMS: A Subculture-Based Multilevel Analysis. Information Systems Research 22(1):39-59. http:// dx. doi. org/ 10. 1287/ isre. 1080.0214

\section{Full terms and conditions of use: http://pubsonline.informs.org/page/terms-and-conditions}

This article may be used only for the purposes of research, teaching, and/or private study. Commercial use or systematic downloading (by robots or other automatic processes) is prohibited without explicit Publisher approval. For more information, contact permissions@informs.org.

The Publisher does not warrant or guarantee the article's accuracy, completeness, merchantability, fitness for a particular purpose, or non-infringement. Descriptions of, or references to, products or publications, or inclusion of an advertisement in this article, neither constitutes nor implies a guarantee, endorsement, or support of claims made of that product, publication, or service.

Copyright (c) 2011, INFORMS

Please scroll down for article-it is on subsequent pages

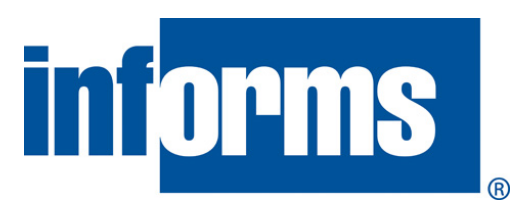

INFORMS is the largest professional society in the world for professionals in the fields of operations research, management science, and analytics.

For more information on INFORMS, its publications, membership, or meetings visit http:// www. informs. org 


\title{
Examining the Strategic Alignment and Implementation Success of a KMS: A Subculture-Based Multilevel Analysis
}

\author{
M. N. Ravishankar \\ School of Business Information Technology, RMIT University, Melbourne, Victoria 3000, \\ Australia, ravi.shankar@rmit.edu.au \\ Shan L. Pan \\ Department of Information Systems, School of Computing, National University of Singapore, \\ Singapore 117543, Republic of Singapore, pans1@comp.nus.edu.sg \\ Dorothy E. Leidner \\ Hankamer School of Business, Baylor University, Waco, Texas 76798, \\ dorothy_leidner@baylor.edu
}

\begin{abstract}
Two important gaps exist in the information systems (IS) alignment research. First, there is scant research 1 on the potential of organizational culture, and specifically subcultures to influence the strategic alignment of IS and organizations. Second, there is a dearth of literature that considers the relationship between alignment and implementation success. In this paper, we address both of these gaps by considering the influence of organizational subcultures on the alignment of a specific IS-a knowledge management system (KMS) - with organizational strategy. Our analysis demonstrates the important roles played by three different subculturesenhancing, countercultural, and chameleon-in the alignment of the KMS. The analysis also underscores the complementary nature of the alignment and implementation literatures and suggests that they should be used in concert to explain the success of an IS. Drawing on our analysis, we build a subculture model, which depicts the intersection of alignment and implementation. From a managerial perspective, the subculture model highlights three different approaches to managing alignment and implementation. From a theoretical perspective, our paper highlights the need for IS alignment models to be modified, so that subunit-level analyses are incorporated. It also illustrates that organizations confront challenges of alignment and implementation simultaneously rather than sequentially.
\end{abstract}

Key words: strategic alignment; information systems implementation; knowledge management systems; organizational subcultures; case study

History: Laurie Kirsch, Senior Editor, Michael Barrett, Associate Editor. This paper was received on August 7, 2006, and was with the authors 17 months for 3 revisions. Published online in Articles in Advance June 12, 2009.

\section{Introduction}

Strategic alignment has long been an issue of importance both in information systems (IS) research and to IS practitioners. A recent Society for Information Management (SIM) study of CIOs found that strategic alignment was considered the most important issue facing CIOs (Luftman et al. 2006). Alignment remains an important issue for CIOs, in part, because failure to align IS with business strategy is believed to result in the failure of many IS initiatives. Particularly in the case of organization-wide (or enterprise-wide) IS initiatives, alignment with the strategic objectives of the organization is an important challenge for modern organizations (Chan et al. 1997a, b; Hirschheim and Sabherwal 2001, Sabherwal and Chan 2001). The IS alignment literature has focused on aligning major IS initiatives with organizational strategy (Chan 2002), with business structures (Ein-Dor and Segev 1982) and with IS structures (Brown and Magill 1994). Yet, in spite of the long tradition of research into IS alignment as well as the endeavours of CIOs to better bridge the gap with senior managers, alignment remains a perennial problem for many organizations.

Whereas existing alignment research proposes a number of formal structural mechanisms an organization needs to incorporate at the top management level to reduce cases of misalignment (e.g., Soh and Sia 2005), research also highlights the influential and long-lasting role played by informal structural elements embedded in the social life of an organization in aligning organizational IS with strategic objectives (e.g., Chan 2002). Against this background, 
it seems feasible that a strong organizational culture, and perhaps more important, the prevailing dominant subcultures within an organization, could also influence the alignment process. While the roles played by the business strategies and business and IS structures of organizations in ensuring successful IS-business alignment have been emphasized in the literature (e.g., Sabherwal et al. 2001), few studies have empirically examined the influence of subcultures (i.e., the influence of the practices, interpretations, and beliefs of various subgroups). Furthermore, although IS literature has considered the IS alignment and IS implementation processes independently, few studies have examined the relationship between alignment and implementation. We believe that it is important to understand the alignment process of a specific IS implementation and how this alignment changes as the system itself is extended. Our study therefore examines the influence of organizational subcultures on the alignment of a particular IS in an organization-a knowledge management system (KMS) - with a goal toward understanding how and why subcultures influence the alignment of the KMS with the organizational strategy at the corporate and business unit levels. Our case analyzes a KMS that is initially well aligned with the organization's strategy but is difficult to implement across organizational subunits. Such a study bears relevance only to KMS but also to other IS implementations that on the surface are well aligned with the organization's strategy and, yet, under the surface, at the subunit level, meet with resistance (Pan and Scarbrough 1999, Pan and Leidner 2003).

\section{Theoretical Foundation}

Alignment (or fit or linkage) between various organizational components is seen as a key to improved organizational performance (Beer et al. 2005, Miller 1992, Reich and Benbasat 1996) and refers to the "degree to which the needs, demands, goals, objectives, and/or structure of one component are consistent with the needs, demands, goals, objectives, and/or structure of another component" (Nadler and Tushman 1980, p. 43). As IS increasingly assumes strategic roles in organizations, IS alignment or strategic IS alignment is seen as the alignment of an organization's IS strategy with the business objectives of the organization (Henderson and Venkatraman 1993, Reich and Benbasat 1996).

The early work on alignment emphasized the identification of those factors that are vital for reaching and sustaining high alignment (e.g., Reich and Benbasat 2000, Chan 2002). The most prominent factors that are shown to facilitate alignment include shared domain knowledge between IS and business executives (Rockart et al. 1996, Reich and Benbasat 2000) and support of senior executives for IS strategies (Luftman and Brier 1999). A popular conceptualization of strategic IS alignment is the strategic alignment model (SAM) (Henderson and Venkatraman 1993, Venkatraman et al. 1993), which is defined in terms of four domains of strategic choice available to an organization, namely, the business strategy, IS strategy, infrastructure, and processes. Most empirical studies have, directly or indirectly, drawn on the four domains of the SAM to operationalize and explain organizations' IS alignment (e.g., Avison et al. 2004, Cragg et al. 2002, Sabherwal et al. 2001). Research has also shown that improved organizational performance resulting from IS alignment is reflected in greater returns on IS investment, greater firm profitability and achievement of competitive advantage (Luftman and Brier 1999, Kearns and Lederer 2004, Peppard and Ward 2004).

More recently, the alignment research has focused less on identifying factors that comprise and/or influence an outcome of alignment but has instead conceptualized alignment as a dynamic process. This dynamic perspective considers alignment as a moving target and views organizations as going through continuous transitory periods of high alignment and low alignment (Brown and Magill 1994, Sabherwal et al. 2001). For instance, Cegielski et al. (2005) observed that e-commerce-based IS strategies, which during the dot-com boom of the late 1990s appeared well aligned with business, eventually gave only meager returns to a number of organizations because IS alignment in these cases remained only a transitory phase. Research also highlights the influence of factors such as uncertain industry environments (Choe 2003, Kearns and Lederer 2004, Miller 1992), mergers and acquisitions (Wijnhoven et al. 2006), and international expansions (Rondinelli et al. 2001) that potentially makes alignment a moving target, rather than just a desired outcome.

Similar in concept to the dynamic perspective of alignment, although not using the term "alignment" per se, research examining IS implementation success across work groups and over time suggests that different groups perceive and respond to the same IS quite differently. IS implementation research often attributes such differences to the embedded informal structures (or informal relationships or informal arrangements) in an organization. These informal structures influence the perceptions of and responses to IS implementation efforts and have important organizational consequences. For example, Schultze and Orlikowski (2004) showed how the quality of customer facing personnel's embedded relationships with their customers was seriously affected by the implementation of a self-serve technology. Likewise, Tyre and Orlikowski (1994) found that experience with a new technology 
often "routinizes" it in the organization, and subsequently, limits and poses barriers to desired future adaptations. Other implementation studies have also highlighted the centrality of informal arrangements by examining relationships, contexts, power structures, and microlevel changes enacted by actors (e.g., Barley 1986, Orlikowski 1996, Robey and Boudreau 1999). One conclusion from these studies is that it is important to look into the social context, including the intentions and actions of key players, when planning an IS implementation (Orlikowski 1993).

In highlighting the informal organizational structures, recent IS implementation research has also considered a multilevel perspective. Lapointe and Rivard $(2005,2007)$ in a multilevel longitudinal analysis of IS implementation in hospitals demonstrated how the consequences of implementation are influenced by both individuals' perceptions of the IS as well as by contextual factors at the individual, group and organizational levels. They concluded that a model at one level is unable to fully predict the outcome of an IS implementation. Only in examining the same phenomenon through models at different levels can one get a more complete picture of the implementation effort and outcomes (Lapointe and Rivard 2007).

Like the implementation research, recent IS alignment research has also begun to emphasize the role played by informal structure (Chan 2002). Structural alignment concerns the degree of fit between an organization's structure and IS decision-making rights and structure (Chan 2002). The research on IS-business structure alignment typically highlights the importance of the need for IS strategies of organizations to be aligned with the organizational business structure (e.g., Jordan and Tricker 1995). Informal structure-the formal and informal teamwork, working relationship, and culture of an organization-has also been found to be important to achieving alignment (Chan 2002). This informal structure is independent of the formal organization structure and is projected to be an enduring aspect of alignment as opposed to the more transient, formal structural alignment.

As noted above, the concept of informal structures does include cultural elements of an organization. However, we believe that by considering organizational culture and organizational subcultures as firmly grounded concepts distinct from the concept of informal structures, more nuanced explanations of their links to the IS alignment process can be obtained. At its deepest level, culture consists of core values and beliefs that are embedded tacit preferences about what the organization should strive to attain and how it should do it (DeLong and Fahey 2000). These tacit values and beliefs determine the more observable organizational norms and practices that consist of rules, expectations, rituals and routines, stories and myths, symbols, power structures, organizational structures, and control systems (Bloor and Dawson 1994, Johnson 1992). Unique values, beliefs and practices also often exist at various group/subunit levels, which can be best described as subcultures. Therefore, considering the manifestations of culture, specifically subcultures, adds an important subunit-level perspective to the alignment literature that has thus far assumed that with appropriate organization-level coordination, such as effective communication between the CIO and CEO and the linking of business and IS missions and plans, and the sponsoring of IS projects by high-level managers, the success of IS initiatives will follow.

In summary, it appears to us that an understudied component in alignment research is that of organizational subcultures and the influence they exert on the alignment process. Implementation research too makes clear that cultural factors at subunit levels influence implementation outcomes. Moreover, most IS alignment studies implicitly assume homogeneity of the organization, and therefore anchor their analysis at the organizational level. Such analyses ignore the influence of subunit factors, when these factors might influence the misalignment of a system in parts of the organization. Also, as noted earlier, very few IS studies explicitly consider the relationship between alignment and implementation. Taking these factors into consideration, we propose a dual-level analysis that considers the influence of organizational subcultures on the alignment of a given IS - that of a KMSwith both the organizational business strategy at the corporate level and with the strategies in specific business units.

\section{Research Methods}

Using a case study method, we adopted the approach of "soft positivism"1 or "scientific realism" (Kirsch 2004, Madill et al. 2000). This approach allowed us to conduct the data analysis with certain expectations based on prior theory, while also allowing some unexpected findings and explanations to emerge from the data, as is more typical of interpretivist approaches. We explain our case study approach below.

\section{Underlying Assumptions}

We approached our fieldwork at ITS, an India-based global information technology (IT) services and consulting company, with a premise that subcultures exist, that subcultures influence alignment and implementation, and that subcultures are identifiable using

\footnotetext{
${ }^{1}$ Our use of the term "soft positivism" differs from its usage in the legal fraternity, where it is used to indicate a particular intellectual position about the relationship between laws and morality (Mitrophanous 1997).
} 
an existing theoretical lens. This position captures the positivism inherent in our study. Accordingly, our study draws on Martin and Siehl's (1983) characterization of organizational subcultures as consisting of three forms: (1) an "enhancing" subculture where the values of the dominant organizational culture predominate, (2) an "orthogonal" subculture where the values of the dominant culture coexist with values and assumptions unique to the subculture, and (3) a "countercultural" subculture whose behaviors and artifacts reveal values and assumptions that directly pose a challenge to the dominant organizational culture. Drawing on this categorization, we objectively studied the KMS alignment process through the subculture lens, anticipating different alignment phenomenon based on different subcultures.

At the same time, because organizational research has exposed the dangers inherent in taking a purely functionalist perspective of cultural attributes of groups (Alvesson 1987, Van Maanen and Barley 1984, Young 1989), we also recognized that subcultures may have their own unique characteristics unrelated to any theoretical classification offered in the organizational literature. We were thus open to the softer or interpretivist position that the subcultures existing at ITS as experienced by ITS employees may not necessarily follow any of Martin and Siehl's (1983) categories. We therefore sought to unveil the emerging categories through the perspective of our informants using a soft or a subjective mode of analysis.

Our analysis of the influence of subculture on alignment and implementation also combined positivist and interpretivist approaches to analysis. We first took existing research on alignment and implementation factors and analyzed the factors present or lacking for each subunit. This aspect of the analysis implied a positivist approach of deciding, in advance, expected factors and assessing based on informant comments whether the factors were, or were not, experienced. Following this, we used a more interpretivist approach in drawing conclusions about the relationship of alignment and implementation. It was this aspect of the analysis that enabled us to offer a new perspective of "subcultural alignment," detailed in the theoretical implications section. The positivist stance gave our study the necessary initial focus, whereas the softer stance gave us the freedom to develop themes and theoretical categories without having to force the data into existing themes.

\section{Company Background}

ITS, a pseudonym, is the company that we studied. ITS is an India-based global IT services and consulting company that employs more than 50,000 people across 10 countries. It has a client base of more than 400 global companies, including a number of Fortune 500 companies. ITS offers technology solutions in areas that include software development, application management, system integration, enterprise solutions, embedded systems, engineering services, and e-commerce.

Structurally, ITS is organized into a number of independent business units called vertical units (VU) and horizontal units (HU), which, respectively, correspond to two key dimensions of business. The first dimension is the "vertical dimension," which recognizes that the nature of knowledge required to produce quality software for one industry, such as the automobile industry, is quite different from the kind of knowledge required to write software for another industry, such as the financial services industry. The second dimension is the "horizontal dimension," which ensures services in specific technology competencies. In addition to these independent VU and HU, ITS has also established around 30 smaller units known as offshore development centers (OSDCs), with each OSDC unit having longterm relationships with a specific client organization. Established in conjunction with the client organization, they function almost as offshore extensions of the client organization, are independent profit centers, and are relatively isolated from other ITS business units.

\section{Case Access and Data Collection}

ITS had only recently implemented a KMS when we proposed our research project to the company's top management team and they extended their full support to our fieldwork plans. Given that we had no personal stake in the implementation, they showed a keen interest in getting our perspective of the organizational consequences of their KMS. The KMSdubbed "KMaster"-was developed in-house at ITS by a dedicated knowledge management (KM) team. In the initial few months, the organization's KMS was reserved only for the business development and presales/sales personnel, and a few project managers, all of whom worked in the corporate office. We shall refer to this KMS user group as the corporate unit. The KMS was subsequently extended and offered to the technical community in the organization, which included the VU, HU, and OSDC units. Reflecting this in our fieldwork, in addition to the corporate unit, we have considered the implementation of the KMS in three other units: a vertical unit called ITS-VU, a horizontal unit called ITS-HU, and an OSDC unit called ITS-OS.

The first author conducted fieldwork in these ITS units in India for five months. Multiple qualitative data sources were used, including documents, e-mails, Internet, field notes, and KM artifacts. We were given access to internal company documents, including minutes of the various meetings conducted by the KM implementation team. The fieldwork also involved 
Table 1

Position and Number of Interviewees

\begin{tabular}{|c|c|c|c|}
\hline Role & 1st interview & $\begin{array}{c}\text { Followup } \\
\text { (face to face/ } \\
\text { telephone/e-mail) }\end{array}$ & Total \\
\hline $\begin{array}{l}\text { Software developers } \\
\text { (VU: 11, HU: 6, OS: 7) }\end{array}$ & 24 & 8 & 32 \\
\hline $\begin{array}{l}\text { Middle-level managers } \\
\text { (VU: 3, HU: } 3,0 \mathrm{OS}: 5 \text { ) }\end{array}$ & 11 & 3 & 14 \\
\hline $\begin{array}{l}\text { Senior manager (chief architect } \\
\text { of the KM project) }\end{array}$ & 1 & 2 & 3 \\
\hline $\begin{array}{l}\text { Research analysts } \\
\text { (KM implementation team) } \\
\text { attached to (VU:2, HU:1, OS:1) }\end{array}$ & 4 & 2 & 6 \\
\hline Top management & 2 & 3 & 5 \\
\hline Total & 42 & 18 & 60 \\
\hline
\end{tabular}

observation of people in various work and nonwork related activities, during which time many informal conversations ensued. These informal conversations covered many different topics, including discussions about the KM artifacts or about documents presented at a previous company seminar. For instance, looking at artifacts such as graphs of KMS usage statistics in the various business units, we often got into informal discussions with employees about what the graphs indicated. During fieldwork, the first author was also present at some of ITS's internal meetings and presentations.

An important source of data was 42 in-depth interviews with members of project teams, mainly from ITS-VU, ITS-HU, and ITS-OS. The interviewees included software engineers, senior software engineers, project managers, technical analysts, KM implementation team members, business unit heads, vice presidents (VPs), and directors of the company. All the interviews were recorded and transcribed. The interview questions largely concerned the role of the interviewee, his or her understanding of and response to the KMS. The first round of interviews comprised of direct face-to-face interactions, while the follow-up interviews were face to face or telephonic or email based. The interviews are summarized in Table 1. Furthermore, following Yin (2003), we record in Table 2 the steps taken to ensure reliability and validity during the study.

\section{Data Analysis}

At the end of five months of fieldwork, we examined the data closely to look for possible subcultural affiliations. To assess subunit subculture, we needed to understand the informants' feelings about the organization as a whole. To this end, we read through the interview transcripts and the recorded on-field observations and came up with themes in the informants' comments and feelings about ITS. Four themes emerged: the feelings about the wisdom of top management decisions, feelings about the importance of cooperation across the business units, feelings about IT-based, top management sponsored quality initiatives, and feelings about communication and information openness (see Appendices A and B). When coding for these themes, we grouped similar ideas together.

Next, to get a closer perspective of ITS-VU, we triangulated data from three main sources: (1) interviews and observations at ITS-VU, (2) interviews with informants in the rest of the company, and (3) the minutes of the KM implementation team's meetings, which discussed in considerable detail the responses to the KMS implementation in the various business units. The data was open coded to better understand ITSVU's characteristics. Common statements were used to form four provisional themes, which best described

Table 2

Steps to Ensure Construct Reliability and Validity (Yin 2003)

\begin{tabular}{|c|c|c|}
\hline \multicolumn{2}{|c|}{ Reliability through } & Validity through \\
\hline 1. Case study protocol & 2. Case study database & 1. Multiple sources of evidence \\
\hline List of field-work locations & Recorded audiotapes & Field notes; interview transcripts; telephone and e-mail discussions; \\
\hline $\begin{array}{l}\text { Informant profiles and contact } \\
\text { information }\end{array}$ & Interview transcripts of each unit & $\begin{array}{l}\text { KM artifacts; information available on ITS website } \\
\text { 2. Establishing chain of evidence }\end{array}$ \\
\hline $\begin{array}{l}\text { Representative list of interview } \\
\text { questions }\end{array}$ & $\begin{array}{l}\text { Transcripts of e-mail and } \\
\text { telephonic discussions with } \\
\text { informants }\end{array}$ & $\begin{array}{l}\text { In the case description, we have cited extensively from the contents } \\
\text { of the case study database. "The circumstances of each data } \\
\text { collection activity" was carefully recorded, and the data collection }\end{array}$ \\
\hline $\begin{array}{l}\text { Possible "informant types" and } \\
\text { strategies to handle them. Ex: } \\
\text { How to interview a very }\end{array}$ & $\begin{array}{l}\text { Field notes: Impressions of } \\
\text { informal conversations with } \\
\text { informants during fieldwork }\end{array}$ & $\begin{array}{l}\text { closely followed the case study protocol (Kirsch 2004). Thus the } \\
\text { chain of evidence presented helps link the empirical material with } \\
\text { the findings }\end{array}$ \\
\hline patronizing informant? & & 3. Review of case drafts \\
\hline $\begin{array}{l}\text { List of other potential themes to } \\
\text { be explored in the interview }\end{array}$ & $\begin{array}{l}\text { Company documents relating to } \\
\text { KMS implementation and } \\
\text { statistics of KMS use in different } \\
\text { units }\end{array}$ & $\begin{array}{l}\text { The initial draft of the case was reviewed by three informants who } \\
\text { observed that the draft offered useful insights. They also } \\
\text { recommended some changes. The head of the KM team, a senior } \\
\text { VP, and a project manager reviewed the drafts. }\end{array}$ \\
\hline
\end{tabular}


ITS-VU members' perceptions, attitudes, and relationship with the larger organization (see Appendix C). We then consolidated the provisional themes to create a more abstract and theoretical theme, which we called a "supporting unit." In other words, the common thread running through the four themes was the members' support of the actions and espoused values of the top management team, following which we created the "supporting unit" theme. By travelling back and forth between the abstract theme and the categories described by Martin and Siehl (1983), we determined that the "supporting unit" fit with the description of an enhancing subculture.

Similarly, we considered all the primary and secondary data corresponding to ITS-OS (see Appendix D). The ITS-OS data revealed that members' thinking directly contrasted with the top management mandated beliefs, and therefore posed a considerable challenge to the aims of the KMS implementation. Following this, we created the "opposing unit" theme, which demonstrated the characteristics of a counterculture highlighted by Martin and Siehl (1983).

One category from the subcultural classification of Martin and Siehl (1983) - the orthogonal subculturedid not appear to be consistent with the data (see Appendix E). Although we were tempted to theorize the ITS-HU data as an orthogonal subculture, in reality, the themes underpinning the data did not show strong subcultural tendencies of its own but simply adapted to subunit environments. This led to the inductive emergence of a new subcultural category-the chameleon culture. ${ }^{2}$

Finally, we looked for ways in which the subcultural categories related to each other and also engaged in a subjective analysis of their influence on the KMS implementation. In the interviews and analysis, we were sometimes confronted with contradictory evidence. For instance, one informant at ITS-OS suggested that responses to the KMS in ITS-OS were influenced by the nature of their agreements with the client organization and not by subcultural factors. Such contradictions were mostly resolved by asking the concerned informant to clarify and explain further and by cross-checking with other sources of evidence. A more detailed description of the various themes in the three business units is available in Appendices C-E.

At this stage in the analysis process, we had looked for indications of alignment and implementation success purely from a subcultural perspective. We then drew on a literature review to create a theoretically grounded list (displayed in Tables 4 and 5) of important alignment and implementation factors at different levels. Examining the subcultural categories in the

\footnotetext{
${ }^{2}$ We thank reviewer 2 for suggesting the term "chameleon culture" to describe this subculture.
}

light of this list helped us to further our analysis of why the units had different experiences of the KMS.

\section{Case Description}

The decision to implement a KMS in 2002 was taken by the CEO. The top management team created a fulltime 10-member team (or unit) called strategic unitKM initiative (SU-KMI) consisting of software developers and marketing personnel from the IS and marketing departments, respectively. The head of this central KM implementation team reported directly to the president of the organization. The central KM team's mandate was to try and make sure that the clientfacing sales and business development personnel in the corporate unit had the requisite up-to-date information when meeting potential clients. Therefore the focus of the KMS was on building repositories that contained case studies of past projects, presentations to clients, organizational best practices, etc. The KMS contained material such as proposals and project information classified and catalogued into business domains, technology domains, and competencies. The $\mathrm{KM}$ team requested and obtained this information from the various project teams that were involved in executing projects and providing solutions to clients. The KM implementation team also created a help desk comprising four of its members to assist individuals using the KMS. They took queries from the sales and business development members and got back with solutions while the requestors waited online. The help desk service was further enhanced to an automated integrated voice recognition (IVR) system that took care of repetitive queries from the sales and business development community. The head of the KM implementation team gave an example of a typical urgent query from a sales executive: "I urgently need a list of all the mainframe migration projects we have done at ITS."

Since its implementation, the KMS has undergone substantial extension. The KMS, initially developed for the corporate unit, was subsequently offered to the technical community in the organization, which currently consists of more than 25,000 members and includes software developers, project leaders, and project managers in the different VU, HU, and OSDC units. This extension of the system involved both adding features and expanding the user base. New features included applications such as the ITS repository, K-Phone, K-Transmit, etc. (see Table 3). Currently, the central KM team through KMaster offers a host of IT-based applications and innovations, which encourage members of all business units to share the knowledge gained during the course of their projects. In the perception of the top management team, middle-level managers, and KM team, the organizational KMS has 
Table 3

Features of ITS's KMS

\begin{tabular}{|c|c|}
\hline KMS features & Description \\
\hline ITS repository & $\begin{array}{l}\text { Contains knowledge resources classified according to category (e.g., best practices, domain, technology, etc.). Also contains project } \\
\text { profiles, ITS patents, and an online library. }\end{array}$ \\
\hline K-Transmit & $\begin{array}{l}\text { Members at all levels in the organization spend significant time reading and responding to e-mails. The KM team latched on to this } \\
\text { practice and modeled the "K-Transmit" service around it. Through "K-Transmit," queries posted by members are channeled to the } \\
\text { mailboxes of the right audience, and their e-mail replies are tracked and logged in the repository. Thus, with "K-Transmit," the } \\
\text { knowledge otherwise floating around gets logged at one place. }\end{array}$ \\
\hline K-Phone & $\begin{array}{l}\text { K-Phone is an off-the-shelf SMS (mobile messaging) technology to facilitate requesting of key documents by members while on the } \\
\text { move. This document-request-and-delivery service is automated with inexpensive technology and small programming effort. }\end{array}$ \\
\hline K-Skool & $\begin{array}{l}\text { These are tacit knowledge-sharing sessions organized across the organization. Topics chosen for these sessions are contemporary } \\
\text { and interesting to a cross section of members. These sessions serve two prime purposes: (1) documenting tacit knowledge of the } \\
\text { members while they share their experiences and (2) creating awareness about KM and its services. }\end{array}$ \\
\hline Help desk service & A dedicated team attends to the queries and requests of the members, thus trying to make this initiative more reachable and useful. \\
\hline KM sharing sites & $\begin{array}{l}\text { To accommodate the already existing internal KMSs of different business units on the organizational KMS, the KM implementation } \\
\text { team hosts the internal websites (that manage knowledge at the business unit level) of the different business units on KMaster. } \\
\text { These sites are called "sharing sites" and some business units now have sharing sites on KMaster. }\end{array}$ \\
\hline
\end{tabular}

two main goals. First, it helps members solve everyday work-related issues more efficiently. According to a senior project manager at ITS:

As a company, when you grow very fast often you won't even know what is happening in some other part of the company. If you are a developer, you may have struggled over a problem for weeks together and you may come to know only later that some other guy in the company who had the same problem in his project has already come out with a good solution (and you did not even know about it!). So the need of a strong $\mathrm{KM}$ support is extremely essential in such cases.

Second, the top management feels that from a strategic viewpoint, breaking in to some of the highly decentralized business units (or silos) and incorporating their knowledge into the KMS is essential. Through the KMS, the organization hopes to build on the project experiences of the various business units, so that it can strategize and offer a wider range of services to clients in the future.

Members of the central KM team have taken up the responsibility of ensuring that all business units support and contribute to the KMS. The KM team periodically conducts KM meetings in all the business units, organizes knowledge-sharing sessions, advertises on the organizational intranet, sends out quarterly newsletters and identifies volunteers in each business unit who can champion the KMS in their respective units. The head of the KM team noted that they were stressing the importance of the KMS by telling members how they could move ahead in their careers faster by identifying with and contributing to the organization's endeavor to create and capture knowledge:

We are telling all members that so far we considered as invaluable those people who got the company a lot of good projects. We are saying that from now on we will also give importance to the performance of members who help create knowledge. So we will keep track of such people and help them go up faster.

In summary, while the initial focus of the KMS was the corporate unit, the subsequent extensions to the system also brought into focus the VU, HU, and the OSDC units. To date, the KMS implementation has met with the most success in the VU, with mixed success in the HU, and with little success in the OSDC. We consider experiences from each of these subunits. First, we present the case ITS-VU, a 1,000-member strong unit that works on application development and maintenance projects for clients belonging to a specific industry segment. Most of the project teams and members at ITS-VU work in a "one-off project" mode, completing one project and taking up the next one, which usually involves a different client in the same unit. Then, we consider the KMS implementation of ITS-HU, a 750-member strong unit that takes up projects involving a particular technology competency. Members belonging to ITS-HU typically are assigned to projects in various business units that require skills in this technology domain. On completing one project in a business unit, members move to some other project in a different business unit. Last, we present the case of ITS-OS, a 400-member strong OSDC unit whose client is a leading organization in the financial industry. Unlike the "one-off project" mode of ITS-VU, ITS-OS has a long-term relationship with its client organization.

\section{Analysis}

Our analysis focuses on the experiences of the three business units (ITS-VU, ITS-HU, and ITS-OS) with the KMS as separate cases. We first present a within-case analysis of the subcultural patterns and their role in the respective unit's KMS experience. We then present 
a cross-case analysis, which examines the alignment and implementation factors present in each of the three business units, as well as in the corporate unit.

\section{The Case of ITS-VU}

Members of ITS-VU reported that they look up to top management for guidance and inspiration and that they strive to embody the values espoused by top management. They viewed themselves as embodying the "real" culture of ITS and maintained a strong identification with the corporate office. A software engineer noted:

As the outsourcing phenomenon proliferated, the organization created a number of business units to meet the growing demand for quality IT services. For business reasons, many of these units have to remain isolated from the organizational mainstream. But here at ITS$\mathrm{VU}$, there are no such compulsions. Members strongly associate themselves with ITS and grab every opportunity to get noticed at the organizational level.

Moreover, members of ITS-VU reported that new strategies initiated by the top management typically are met with enthusiastic endorsement even if some projects create an initial uncertainty. As a project manager explained it:

Our mental frame of reference is always the larger organization. So though we may take some time to get used to new expectations arising out of a new strategic focus or a industry buzzword, we fall in line sooner rather than later.

In this sense, ITS-VU can be characterized by what Martin and Siehl (1983) refer to as an "enhancing" subculture where the values of the broader organizational culture predominate. The enhancing subculture had maintained a strong identification with the corporate office, and the members were positively inclined to accept strategic initiatives championed by the senior management. Consistent with this subcultural tendency, members at ITS-VU have responded enthusiastically to the rollout of KMaster. Informants recalled that since the KMS was rolled out, they have been excited by the applications available on KMaster and accessed them frequently. A senior software engineer explained:

Initially when the KMS was implemented, we were very curious about what KM was and how it was going to benefit us and the organization. Once "K-Skool" sessions were launched under the aegis of organizationwide KM, we began to really see the benefits. "K-Skool" sessions are primarily tacit knowledge sharing sessions, where we meet, brainstorm, and discuss a wide range of cutting-edge technical issues.

Many members from ITS-VU registered for these sessions and attended them. Informants found these sessions very useful and reported that they motivated them to contribute to the KMS. According to a system engineer who had attended a K-Skool session:

After attending K-Skool, I am now a very keen contributor to KMaster. I upload a lot of software codes to KMaster that can be reused and so other developers find them very useful. I have gotten many "thank you" e-mails from members in various units.

Most informants at ITS-VU felt that with the implementation of the KMS, they could easily recognize the immense potential of sharing knowledge with members from other business units. A project manager explained:

My previous project was completed in 4 months flat and we just moved on to the next one. So we are very keen that the organization benefits from the knowledge created in each of our projects. So over the years, we have tended to get actively involved with the organization's KM strategy. Moreover, I strongly feel the KMS is very beneficial to our unit as well.

Since its implementation, members of ITS-VU have contributed reusable software codes, project best practices, and case studies to the various KMaster repositories. They also often posted their technical project-related queries to the many discussion forums set up on the organization wide KMS, and claimed to get quick replies from members of other business units working in similar technology domains.

\section{The Case of ITS-HU}

As noted earlier, members at ITS-HU were assigned to different business units during different projects. The need to quickly adapt to a new unit seemed to have fostered a culture of adaptability and flexible team-focused individuals within the unit. ITS-HU can be said to have a "chameleon" culture. The notable feature of this "chameleon culture" was its ability to adapt to the subculture of the unit it was assigned to. Indeed, informants at ITS-HU felt that one of their main characteristics was their ability to integrate into the cultures of different business units. According to a senior software engineer:

Since we are constantly shuttling between different business units, we try to fit well into different environments. As a result, we do not have any common practices or strong beliefs that can be called "uniquely ITS-HU." But many of the business units we work in have their own norms and practices and for the time we are there, we religiously follow all of them.

Another software engineer echoed:

In a recent project, I worked in a business unit where people were always making sarcastic remarks about the organization's mission statements and quality processes. After a period of time, I found myself making similar remarks. In my current business unit, everybody is dead serious about quality processes and now I find myself totally in agreement with them. 
The response of the chameleon culture at ITS-HU to the KMS was mixed and dependent on whether the unit to which an individual was temporarily assigned valued the KMS or not. Informants felt that their use of the resources and contribution to KMaster was extremely high when they worked on projects in certain business units. A senior software engineer commented:

When I first came to know about our KMS, I was working on a project in one of the VU. My project manager (from ITS-VU) I remember was extremely excited about the KMS. During that project, we interacted quite a bit with members from other business units through KMaster. We extensively used the discussion forum repositories that featured various technologies and domains, to discuss some of the pain-points in our project.

Other software engineers who had worked in a three-month project in ITS-VU explained that during that project, they created a series of generic software codes, which were likely to be used routinely in many applications. Following the number of messages posted by the KM implementation team on the organizational intranet about how knowledge sharing can reduce project completion times, they neatly classified all the generic codes they had created and uploaded them to the organizational KMS. In essence, the project managers from the ITS-VU unit had acted as evangelists for the systems, enthusiastically promoting it to the new temporary members from ITSHU. However, the members of ITS-HU only appeared to engage in the KMS while they were assigned to teams within ITS-VU. Engineers assigned to work temporarily for an OSDC unit expressed quite different experiences. Three software engineers, who were part of a project in an OSDC unit for close to a year, explained that they hardly ever accessed the organization-wide KMS. One of them noted:

In the OSDC project, organizational KM was definitely not on top of our minds. Even when we had technology domain related queries that perhaps could have been answered by an expert here in ITS, we chose to post a query in the KM portal on the client organization's intranet to which we had been given access.

In short, while members in ITS-HU appeared to have an open-mind toward supporting ITS's intent to create and build a strong KMS platform, they tended to participate very frequently or infrequently in $\mathrm{KM}$ activities depending on what they called the "culture" of different units. In their experience, whenever they were part of a project in an OSDC unit, they rarely shared knowledge via KMaster because the "culture there was different." However, whenever they worked on a project in a VU, they were more involved with the KMS. A senior software engineer at ITS-HU explained:
The KM team expects us to contribute case studies, reusable artifacts and so on to KMaster, and they often wonder why we don't give it to them. How interested we are in $\mathrm{KM}$ at any given time largely depends on the general attitude towards KM in the business unit we move in to. At present, the feeling in this unit (my present location) is that the $\mathrm{KM}$ initiative is concerned purely with numbers. So there is a lot of resistance to contribute.

According to a senior project manager:

Overall, I think the organizational KMS is a great idea and I see its value to us, but over the years we have simply followed what we see in our assigned units.

\section{The Case of ITS-OS}

Culturally, members of ITS-OS identified with the values of their clients and lost attachment to the values of ITS. As captured in the informants' quotes below, the culture at ITS-OS coincided with what Martin and Siehl (1983) refer to as a "countercultural" subculture. A senior VP of ITS explained:

Let us say a team works on a project for a leading global financial firm. Now we (ITS) want to retain some of the knowledge that we have gained from the project with this financial firm. So we want the team to remain rather than keep moving from one project to another, like what happens when the first project is for a global financial firm and the next one is for (say) a global manufacturing firm. So to maintain the continuity and knowledge retention, we set up OSDCs. Now we have about 30 of them. In an OSDC setup naturally the client has a major say, and so we become tuned to the client culture, language, etc., and the OSDCs become slightly removed from the rest of the organization.

Informants at ITS-OS felt that owing to the longterm relationship with a single client organization, they tended to be more attached emotionally to the client organization, and that in everyday organizational life they often mentally invoked the client organization, its logo, its mission statement, etc., and the prestige associated with it. Since the implementation of the KMS, the 400 members in ITS-OS have very rarely contributed or accessed any of the IT applications available on the organization-wide KMS. A project manager explained:

Yes, I am aware that the organizational KMS exists. In fact, I support it and think it is very good for our unit too. But somehow it has become just a peripheral event. It has never touched us, or perhaps it is more accurate to say that we have not allowed it to touch us. Having central knowledge repositories arranged according to various technologies and domains and keeping them updated is a very good idea, but I can say for sure that people from our OSDC have very little to do with it. 
Informants in ITS-OS explained that some of them still attended a number of meetings conducted by the $\mathrm{KM}$ team where they are asked to contribute reusable software codes, documents featuring the best practices in ITS-OS, case studies, etc. But most informants claimed that the top management often "pushed" initiatives such as KMS to make sure that ITS-OS does not become too independent. Some also recollected that a few years back, the top management team asked everyone at ITS-OS to follow an organizationwide, quality-related best-practice program, which involved extensive documentation:

As with the KMS now, we opposed it totally then. Every now and then someone at the top comes with a bright idea to interfere!

Another reason, which informants gave for their limited experience with the KMS was the nondisclosure agreements (NDA) with the client organization. These NDA clearly restricted the sharing of sensitive knowledge privy to the offshore team with the rest of the organization. However, the head of the KM team pointed out that apart from clientspecific forms of knowledge, there was a vast body of useful technical knowledge that could be shared via KMaster, but still remained unshared. When asked to reflect on this, many informants agreed. A senior technical manager said:

Yes, given that we have the NDA it does become easy for us to hide behind it and say that everything is protected and KMS is not for us. We do it all the time, but you must understand that the culture here is different.

According to a senior VP at ITS-OS, the isolation of ITS-OS from the organizational mainstream and its reluctance to play a significant role in the organizational KMS was a compromise the organization had to face up to. He felt that a special environment was in place at ITS-OS where members prided themselves so much on their relationship with the client organization that to them, the KMS was far removed from their everyday life. Such a perception among members at ITS-OS, he opined, needs to be somehow accommodated so that members in ITS-OS are more forthcoming toward the KMS.

\section{A Cross-Case Analysis of the Alignment and Implementation of the KMS}

Considering the above within-case analyses of the three units in tandem with the KMS implementation in the corporate unit, we now present below a cross-case analysis that also incorporates the key theory-driven factors underpinning alignment and implementation (see Tables 4 and 5 for an overview of this analysis).

\section{A Cross-Case Analysis of KMS Alignment}

The first phase of ITS's KMS was geared solely toward the corporate unit and was marked by its focus on ensuring that sales and business development personnel are provided with up-to-date information when meeting potential clients. This focus of the KMS was reflective of the company's endeavors to increase its client base and grow as an IT organization. Looking at Table 4, we see that the underlying strategic focus of the corporate unit and the KMS was well aligned following the preconditions for strategic alignment identified in existing IS research (Chan 2002, Henderson and Venkatraman 1993, Luftman and Brier 1999, Rockart et al. 1996). Not only were formal structures in place to ensure alignment, but it was also backed by the shared commitment of the sales and business personnel, who formed the organizational counterparts of the KMS and reported to the top management team. Thus, this alignment was both along the "intellectual dimension" (well-spelt-out aims of the KMS and the presence of structures to support the aims) and "social dimension" (shared commitment) (Reich and Benbasat 1996, 2000). Furthermore, in having a permanent full-time 10-member KM implementation team composed of members with both IS and business skills, the KMS implementation also followed the preconditions set out for achieving "IS structural alignment" (Chan 2002, Tavakolian 1989).

However, from an alignment point of view, as the scope and aims of the KMS expanded beyond its original intent and aimed to penetrate the technical community - the software developers and project managers in the VU, HU, and OSDC units-the existing strength of the strategic alignment was no longer sufficient to maintain the success of the KMS. Instead, responses grounded in the enhancing, countercultural, and chameleon subcultural affiliations of the various business units became a key to continued alignment.

As seen in Table 4, most of the major factors influencing strategic and structural alignment were met across the three business units: there were representatives on the KM team who had formally worked in each of the three units, hence creating a shared domain knowledge between the KM team and business units. Moreover, business unit managers in each of the units expressed support for the KMS and believed that it would help their respective business unit. Also, each of the business units was operating in a stable environment, experiencing growth both in clients and in services provided. In spite of these strategic and structural factors that are key to alignment being met, the responses of the three units to the KMS varied starkly. Looking into Table 4, the only alignment factor that is not similar across the three units is that of favorable informal structure. 
Ravishankar, Pan, and Leidner: Examining the Strategic Alignment and Implementation Success of a KMS

Table 4

List of Key Alignment Factors and Evidence from the Cases

\begin{tabular}{|c|c|c|c|c|}
\hline \multirow{2}{*}{$\begin{array}{l}\text { Key factors } \\
\text { influencing alignment }\end{array}$} & \multicolumn{4}{|c|}{ Evidence from the cases } \\
\hline & Corporate unit KMS & ITS-VU & ITS-HU & ITS-OS \\
\hline $\begin{array}{l}\text { Support of senior } \\
\text { executives for IS } \\
\text { (Luftman and Brier } \\
\text { 1999) }\end{array}$ & \multicolumn{4}{|c|}{$\checkmark$ The KMS was the CEO's idea. The senior executives supported the system in all the units. } \\
\hline $\begin{array}{l}\text { IT management } \\
\text { sophistication } \\
\text { (Sabherwal and Kirs } \\
\text { 1994) }\end{array}$ & \multicolumn{4}{|c|}{$\begin{array}{l}\checkmark \text { ITS is an IT organization that is very experienced in managing systems. Furthermore, all the business units at ITS managed } \\
\text { their own IT systems and had experience with system design and implementation at the unit level. }\end{array}$} \\
\hline $\begin{array}{l}\text { Shared domain knowledge } \\
\text { between IS and } \\
\text { business executives } \\
\text { (Reich and Benbasat } \\
\text { 2000, Rockart et al. } \\
\text { 1996) }\end{array}$ & \multicolumn{4}{|c|}{$\begin{array}{l}\checkmark \text { The KM team was composed of members with experience in client facing roles. The KM team had members with previous } \\
\text { experience of working in different units. In other words, the KM team was composed of members who shared domain- } \\
\text { specific knowledge with members in the three units. }\end{array}$} \\
\hline $\begin{array}{l}\text { Environmental stability } \\
\text { (Choe 2003, Kearns } \\
\text { and Lederer 2004) }\end{array}$ & \multicolumn{4}{|c|}{$\begin{array}{l}\checkmark \text { ITS is seen as operating in a relatively stable environment. The number of projects taken up by all the business units is } \\
\text { increasing gradually and ITS has annual revenues of over US } \$ 1 \text { billion. Most analysts foresee the IT services sector to } \\
\text { grow further and the business environment is generally considered robust and stable. }\end{array}$} \\
\hline $\begin{array}{l}\text { Communication between } \\
\text { business and IT } \\
\text { executives (Reich and } \\
\text { Benbasat 2000) }\end{array}$ & \multicolumn{4}{|c|}{$\begin{array}{l}\checkmark \text { The head of the KM team reported directly to the president of ITS. Furthermore, the KM team members and managers in the } \\
\text { three business units maintained excellent communication both through formal and informal channels and showed } \\
\text { commitment to the strategic aims of the KMS. }\end{array}$} \\
\hline $\begin{array}{l}\text { Connections between } \\
\text { business and IT } \\
\text { planning (Reich and } \\
\text { Benbasat 2000) }\end{array}$ & \multicolumn{4}{|c|}{$\begin{array}{l}\checkmark \text { The KMS was planned to help members in their sales and business development activities. The KMS was designed to help } \\
\text { members work more efficiently. Also, by building on the project experiences captured through the KMS, ITS planned to } \\
\text { offer a wider range of services to clients in the three units. This was seen to help the long-term business prospects of the } \\
\text { three units. }\end{array}$} \\
\hline $\begin{array}{l}\text { Favorable informal } \\
\text { structures (Chan 2002) }\end{array}$ & $\begin{array}{l}\checkmark \text { The working relationship } \\
\text { between the KM team } \\
\text { members and senior } \\
\text { management was } \\
\text { excellent. The KM team } \\
\text { also worked closely and } \\
\text { coordinated with } \\
\text { members in the } \\
\text { corporate unit }\end{array}$ & $\begin{array}{l}\checkmark \text { Members at ITS-VU looked } \\
\text { up to the senior } \\
\text { management and were } \\
\text { inclined to support the } \\
\text { initiatives championed } \\
\text { by senior management }\end{array}$ & $\begin{array}{l}\text { X Members at ITS-HU were } \\
\text { prone to supporting } \\
\text { organizational initiatives } \\
\text { only when assigned to } \\
\text { VUs, but not when } \\
\text { assigned to OSDCs }\end{array}$ & $\begin{array}{l}\text { X Members at ITS-OS } \\
\text { identified more with the } \\
\text { client organization and } \\
\text { disregarded } \\
\text { top management- } \\
\text { supported initiatives }\end{array}$ \\
\hline
\end{tabular}

Whereas the ITS-VU enjoyed an enhancing subculture that appears to have helped the unit assimilate the KMS even if it was not designed originally for them, the counterculture of the ITS-OS and the chameleon culture of ITS-HU seemed to have militated against the alignment of the system at the subunit level. In the case of ITS-OS, even while members stated that they could understand the benefits of knowledge sharing to the organization, they excused themselves from participating based on their belief that ITS-OS should not be contributing knowledge, regardless of its benefits to the larger organization, because of its unique relationships to clients, a relationship not shared, in their minds, by other parts of the organization.

Ironically, many members of ITS-HU had experienced these client relationships in their assignments on OSDC teams. Perhaps best positioned to understand the benefits of a KMS were the members of ITS$\mathrm{HU}$, who had participated on teams within ITS-VU as well as ITS-OSDC. Yet, rather than acting as bound- ary spanners, encouraging the use of the system in the teams to which they were assigned, the members of ITS-HU appeared to have sublimated their own opinions to those of the team to which they were assigned, resulting in an alignment pattern that was difficult to control and manage: members of ITS-HU assigned to VU teams supported the systems while those assigned to OSDC teams did not. In this sense, the system was partially aligned, with the alignment varying both across time and individuals and even to the point of varying by individual across time. The cases of ITS-HU and ITS-OS illustrate that organizational-level strategic and structural alignment does not in and of itself filter down to the subunit level. Unless the subunit has an enhancing subculture, the process of alignment must reoccur at the subunit level.

A Cross-Case Analysis of the KMS Implementation From an implementation point of view, referring to Table 5, it is evident that of the units considered, the KMS implementation was best placed to succeed, and 
Table 5 List of Key Implementation Factors and Evidence from the Cases

\begin{tabular}{|c|c|c|c|c|c|}
\hline \multirow[b]{2}{*}{ Level } & \multirow{2}{*}{$\begin{array}{l}\text { Key factors influencing } \\
\text { implementation }\end{array}$} & \multicolumn{4}{|c|}{ Evidence from the cases } \\
\hline & & Corporate unit KMS & ITS-VU & ITS-HU & ITS-OS \\
\hline Organization & $\begin{array}{l}\text { Perceived maintenance of } \\
\text { current power } \\
\text { structures (Lapointe } \\
\text { and Rivard 2007, } \\
\text { Markus 1983) }\end{array}$ & $\begin{array}{l}\checkmark \text { The system was not } \\
\text { intended to alter power } \\
\text { structures, but to } \\
\text { empower users }\end{array}$ & $\begin{array}{l}\checkmark \text { Members were not } \\
\text { threatened by the } \\
\text { KMS. They also felt a } \\
\text { sense of ownership } \\
\text { toward the KMS } \\
\text { implementation }\end{array}$ & $\begin{array}{l}\checkmark \text { Members were not } \\
\text { threatened by the } \\
\text { KMS, nor did } \\
\text { they feel ownership }\end{array}$ & $\begin{array}{l}\text { X Members saw the system } \\
\text { as a threat to their } \\
\text { independence }\end{array}$ \\
\hline \multirow[t]{4}{*}{ Unit } & $\begin{array}{l}\text { Routinization of IS over } \\
\text { time structures } \\
\text { (Lapointe and Rivard } \\
\text { 2007, Tyre and } \\
\text { Orlikowski 1994) }\end{array}$ & $\begin{array}{l}\checkmark \text { Over time, the system } \\
\text { became an important } \\
\text { component of everyday } \\
\text { work activities }\end{array}$ & $\begin{array}{l}\checkmark \text { Members used the } \\
\text { KMS frequently at } \\
\text { work }\end{array}$ & $\begin{array}{l}\checkmark / X \text { The system was } \\
\text { used only when } \\
\text { members were } \\
\text { assigned to VUs. } \\
\text { It was routinized } \\
\text { at the group, but } \\
\text { not the individual, } \\
\text { level }\end{array}$ & $\begin{array}{l}\text { X Members spoke of how } \\
\text { they had "not allowed it } \\
\text { to touch them" }\end{array}$ \\
\hline & $\begin{array}{l}\text { Shared cultural } \\
\text { interpretations (Robey } \\
\text { and Azevedo 1994, } \\
\text { Robey and Boudreau } \\
\text { 1999) }\end{array}$ & $\begin{array}{l}\checkmark \text { The system was seen as } \\
\text { the top management's } \\
\text { response to the issues } \\
\text { members' faced at work }\end{array}$ & $\begin{array}{l}\checkmark \text { The KMS was } \\
\text { interpreted as a valid } \\
\text { effort to better } \\
\text { manage knowledge }\end{array}$ & $\begin{array}{c}\checkmark / X \text { Members did not } \\
\text { demonstrate any } \\
\text { strong feelings } \\
\text { toward the KMS }\end{array}$ & $\begin{array}{l}\text { X The KMS was interpreted } \\
\text { as a symbol of } \\
\text { top management's } \\
\text { interference }\end{array}$ \\
\hline & $\begin{array}{l}\text { Involvement of users in } \\
\text { design (Baroudi et al. } \\
\text { 1986) }\end{array}$ & $\begin{array}{l}\checkmark \text { The KMS was developed } \\
\text { together with the } \\
\text { client-facing personnel }\end{array}$ & \multicolumn{3}{|c|}{$\begin{array}{l}\text { X Although members were asked for their inputs about the impending system, } \\
\text { they were not involved in its design per se }\end{array}$} \\
\hline & $\begin{array}{l}\text { Exercise of control over IS } \\
\text { implementation (Kirsch } \\
\text { 2004) }\end{array}$ & $\begin{array}{l}\checkmark \text { Members largely directed } \\
\text { the implementation in } \\
\text { the early days of the KM } \\
\text { team }\end{array}$ & \multicolumn{3}{|c|}{$\begin{array}{l}\text { X The well-established KM team supervised and managed the implementation } \\
\text { across the units. Hence the business units did not control KMS } \\
\text { implementation, even though they were used to controlling their own IS }\end{array}$} \\
\hline \multirow[t]{4}{*}{ Individual } & $\begin{array}{l}\text { Cognitive absorption } \\
\text { (Agarwal and } \\
\text { Karahanna 2000, } \\
\text { Lapointe and Rivard } \\
\text { 2007) }\end{array}$ & $\begin{array}{l}\checkmark \text { Members were "in tune" } \\
\text { with applications such } \\
\text { as the help desk service } \\
\text { and IVR system }\end{array}$ & $\begin{array}{l}\checkmark \text { Members at ITS-VU } \\
\text { were involved in the } \\
\text { KMS applications }\end{array}$ & $\begin{array}{l}\text { X The degree of involvemer } \\
\text { system and its applica } \\
\text { lower at ITS-HU and I? }\end{array}$ & $\begin{array}{l}\text { nt of members with the } \\
\text { ations was considerably } \\
\text { TS-OS }\end{array}$ \\
\hline & $\begin{array}{l}\text { Perceived ease of use } \\
\text { (Lapointe and Rivard } \\
\text { 2007) }\end{array}$ & $\begin{array}{l}\checkmark \text { The system was easy to } \\
\text { use and the KM team } \\
\text { made changes as } \\
\text { requested by users }\end{array}$ & \multicolumn{3}{|c|}{$\begin{array}{l}\checkmark \text { When the KMS was developed to include applications for the technical } \\
\text { community, they were perceived as easy to use by members in all } \\
\text { three business units }\end{array}$} \\
\hline & $\begin{array}{l}\text { Perceived usefulness } \\
\text { (Lapointe and Rivard } \\
\text { 2007) }\end{array}$ & $\begin{array}{l}\checkmark \text { The system was originally } \\
\text { designed to meet the } \\
\text { needs of the sales and } \\
\text { business development } \\
\text { teams. }\end{array}$ & $\begin{array}{l}\checkmark \text { Members viewed the } \\
\text { system as very } \\
\text { useful and used it } \\
\text { very often }\end{array}$ & $\begin{array}{l}\checkmark \text { and } X: \text { Members at } \\
\text { ITS-HU felt the } \\
\text { system was useful to } \\
\text { the organization, but } \\
\text { not to themselves or } \\
\text { their unit when they } \\
\text { were assigned to } \\
\text { OSDC units }\end{array}$ & $\begin{array}{l}\checkmark \text { and } X: \text { Members viewed } \\
\text { the system as useful } \\
\text { to the organization, } \\
\text { but not to themselves } \\
\text { or their unit }\end{array}$ \\
\hline & $\begin{array}{l}\text { Users' previous } \\
\text { experience with } \\
\text { technology (Martinko } \\
\text { et al. 1996) }\end{array}$ & \multicolumn{4}{|c|}{$\begin{array}{l}\checkmark \text { Given that IT was an integral part of their work, KMS users were very comfortable using new IT-based } \\
\text { technology. A sales and marketing person or a KMS user in the three business units normally had at least } \\
\text { some experience in using technology applications similar to those offered by the system }\end{array}$} \\
\hline
\end{tabular}

did, in fact, succeed, in the corporate unit given that all the key implementation factors-such as involvement of users in design, user control of implementation, perceived usefulness-were met. Moreover, the system was not originally intended to extend to other areas and was indeed tailored toward the needs of the corporate unit. In the case of ITS-VU, ITS-OS, and ITS-HU, it is clear that the three subcultures and the underpinning shared cultural interpretations (Robey and Azevedo 1994, Robey and Boudreau 1999) played an important role in influencing the success of the KMS implementation. The enhancing subculture, which complemented and reflected the larger organizational culture, was accepting of the KMS in spite of some preconditions to implementation success being violated: the ITS-VU members were not involved in the design and the implementation was entirely controlled by the KM team (see Table 5).

In contrast, while barriers to implementation success at ITS-OS (see Table 5) such as the lack of cognitive absorption of the KMS (Agarwal and Karahanna 2000, Lapointe and Rivard 2007), the inability to 
exercise control over the KMS implementation (Kirsch 2004), the nonroutinization of the KMS (Tyre and Orlikowski 1994) and the perceived challenges to the power structure (Markus 1983, Lapointe and Rivard 2007) were evident, the counterculture further aggravated the challenges and influenced the collective thinking about the adoption of KMS in the unit. Put differently, ITS-OS had identified so much with its client organization culturally that there was no longer a connection, informally speaking, to ITS. Building on the greater attachment to the client organization, the beliefs of the ITS-OS counterculture also influenced the attributions assigned to the top management champions of the KMS. Members in ITS-OS viewed the KMS as an unfair attempt at interference by the top management into the existing fair and just arrangements at their unit level. They believed that the top management forced them into supporting the KMS implementation to stop them from becoming too independent. To this extent, they saw the KMS as having a harmful effect on their perceived high status in the organization and did not believe the top management's assurance of faster career growth in return for participation in KMS. Also, the subculture contributed to the challenges of implementation at ITSOS by encouraging the members to rationalize their noninvolvement with the KMS as vividly depicted in the case of members hiding behind the NDA issue. And while the members of IT-OS recognized the usefulness of the system to the organization, they did not recognize its' usefulness to them personally (see Table 5).

The implementation difficulties of the KMS at ITSOS also throw light on an important issue confronting ITS. Although the very formation of the OSDC units such as ITS-OS helped the company to benefit from knowledge reuse to a limited extent (e.g., having engineers familiar with a client organization permanently assigned to that OSDC unit instead of shuffling them around to other units where they would have to learn about the client's needs before becoming a productive team member), this design led to lower knowledge transfer across units in that the lessons learned within an OSDC unit tended to remain within that unit. This might indeed turn out to be an enduring rather than a transient challenge for ITS. As Ghoshal and Gratton (2002) noted, from an organizational perspective creating isolated profit-centric units often helps reap business benefits. By the same logic, more OSDC units are likely to be created at ITS in the future, further intensifying the countercultural challenge to implementation success.

As with ITS-OS, ITS-HU faced difficulties in ensuring the success of the system on account of various factors, such as the lack of user involvement in the design and implementation of the system, as highlighted in Table 5. Moreover, the chameleon subculture served to further intensify these factors. In some senses, it is troubling that ITS-HU members would endorse the system while working on an ITS-VU team but eschew the same system while working on an OSDC unit team. So strong was the norm of adaptability to the team assigned, that it seems to have suspended their own judgments about the usefulness of the system. Not only was there variance across individuals in the perception of the system's usefulness, the same individual held varied perceptions of usefulness (see Table 5), depending on his or her current assignments. It is important to keep in mind that the members of ITS-HU were performing the same functions when they were reassigned to different units, so it was not that the system was relevant to the tasks associated with one unit but not the other.

\section{Discussion: A Subculture Model of the Intersection of Alignment and Implementation}

The above analysis shows that alignment is best understood in concert with implementation. In other words, it underscores the complementary nature of the alignment and implementation literatures and suggests that they should be used together to explain the success of a system. Drawing on the above analysis, we next build a subculture model depicting the intersection of alignment and implementation. For subcultures best described as Enhancing (Martin and Siehl 1983), alignment at the organization level effectively ensures alignment at the subunit level, as well as fit with individuals' values in the organization. This is depicted pictorially in Figure 1. While factors such as support of senior executives for IS (Luftman and Brier 1999) and IT management sophistication (Sabherwal and Kirs 1994) are clearly important for alignment, and factors such as individuals' perceptions of the system (Lapointe and Rivard 2007) do influence the implementation, an enhancing subculture works in tandem with these factors and creates a positive impact. In a subunit with an enhancing subculture, implementation and alignment processes coexist such that successful alignment at the organization level has a trickle-down effect and

Figure 1 Enhanced Alignment

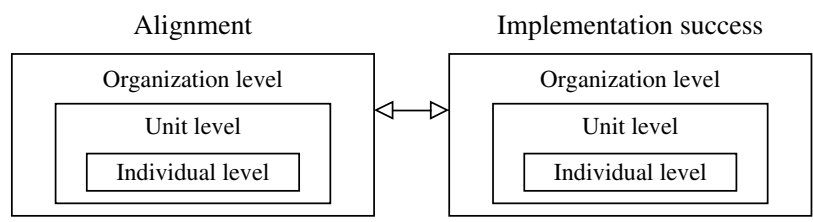




\section{Figure 2 Chameleon Alignment}

Alignment

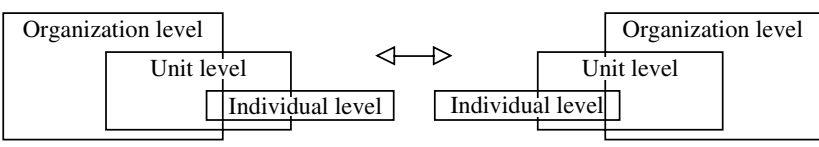

likewise, successful implementation trickles down to the subunit and individual levels. Moreover, alignment and implementation are interrelated such that alignment facilitates implementation, and implementation success helps reinforce alignment.

We argue that additional implementations of a system in different subunits represent a continued case of alignment rather than a new case of alignment. In other words, IT managers should not need to strategically realign a system that has spread from one subunit to another, assuming an enhancing subculture. In such a context, a traditional top-down approach to alignment and implementation is warranted. However, given the complexity of large organizations, one might expect instances of the enhanced alignment to be infrequent.

While a top-down approach to alignment appears to be appropriate in the context of the enhancing subculture, in the context of the chameleon subculture, such an approach would be only partially effective. There is some overlap in culture, and hence effective alignment at the organization level might well contribute to alignment at the subunit level, but only to the extent that at the time of implementation, members of the chameleon unit are engaged in work that is tied to overall organizational objectives as opposed to work that is tied more closely to subunit objectives. Even while the intersection is not complete, effective alignment at the subunit level is unlikely to be possible without alignment at the organization level. Figure 2 depicts the alignment-implementation intersection for the chameleon subculture. In this case, even when the IT and business planning processes are logically connected, domain knowledge is shared between IT and business executives and communication between IT and business executives is excellent (Reich and Benbasat 2000), the chameleon subculture may often work against the objectives of the IS and pose difficulties for alignment and implementation success.
We also note that the most appropriate approach to alignment in the chameleon subculture would appear to be a top-bottom-up approach. Such an approach would mean that the organizational alignment factors and implementation factors would be important to help legitimate the system, but then the IS implementation team would need to try to "sell" the system to individuals, particularly influential individuals, in each subunit to gain individual commitment to the system regardless of the work group to which the individuals were currently assigned. Only then can the system enjoy successful implementation across groups within the subunit. The IS organization would need to understand the professional values held by individuals in different subunits and ensure that the system in some way contributed to improvements in an individual's ability to perform their work (Schultze and Orlikowski 2004).

The third and final form of the subculture model showing the intersection between alignment and implementation is represented in Figure 3 and occurs in subunits exhibiting countercultures (Martin and Siehl 1983). In this context, alignment at the organizational level not only does not ensure alignment at the subunit level, but may actually militate against successful alignment and implementation. Because organizational-level initiatives are treated skeptically by members of the countercultural unit, well-executed initiatives at the organization level are likely to meet with nonchalance at best. In other words, the counterculture may influence the thinking in the unit about adopting the IS, and therefore pose an important barrier to alignment and successful implementation.

In this context of a counterculture, we suggest that the most appropriate approach to alignment would resemble a bottom-up approach to implementation (Ciborra 1992). Ciborra (1992) suggests that the structured guidelines to planning IT to support the business, (e.g., aligning IT) as well as the implementation plans, do not reflect the reality of most successful system design and implementation. Ciborra (1992) suggests instead that firms must allow innovation and tinkering at "the local level" such that individuals are largely responsible for the resulting system, which

Figure 3 Counterculture Alignment

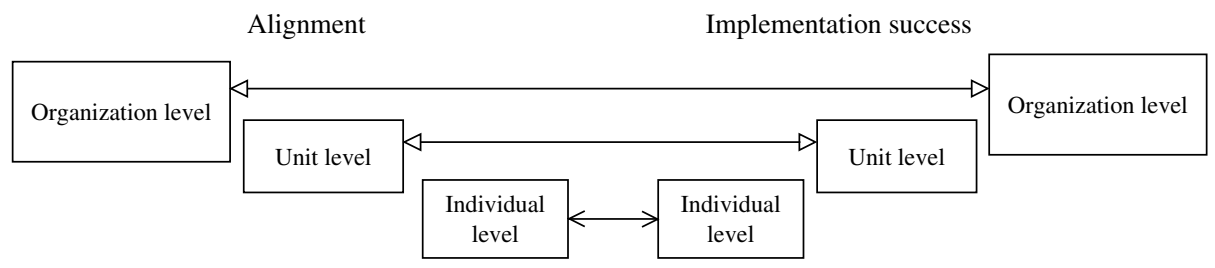


can then move upward in the organization. In ITS's case, one way of promoting innovation at the "ITSOS level" could be to draw on Web 2.0 thinking and to extend the organizational KMS framework to ITSOS. A separate KMS could be developed for ITS-OS, whose responsibility could be taken up exclusively by ITS-OS members. In summary, in the bottom-up approach, each implementation of a system in a new subunit must be treated as a new case of alignment and implementation. Lessons learned from a previous subunit may be helpful, but should not alone define, or constrain, the implementation plan. Members, and not just senior managers within the subunit, must be made owners of the system, such that it is considered their initiative. A summarized analysis of the KMS implementation and alignment issues is depicted in Figure 4.

\section{Theoretical Implications}

Whereas the dynamic theory of alignment suggests that a given system goes through periods of alignment and misalignment (Sabherwal et al. 2001), treating a system holistically as does the traditional view of alignment (Luftman and Brier 1999, Rockart et al. 1996), our findings suggest that a single system spread across units in an organization might simultaneously experience alignment and misalignment. As such, alignment processes cannot be managed solely at the organizational level. Alignment research has a long and rich history. While the factors that help create alignment at the organizational level have been well described (Reich and Benbasat 2000, Rockart et al. 1996, Choe 2003, Kearns and Lederer 2004, Chan 2002, Sabherwal and Kirs 1994, Luftman and Brier 1999), our study suggests that a multilevel analysis of IS alignment is needed. Alignment of an IS in an organization cannot be understood solely by looking at the organizational-level factors. The presence of these factors is not sufficient to guarantee alignment at the subunit level. Theoretically, this suggests that alignment models must be modified to include subunitlevel considerations. Following the empirical insights from our study, one important dimension that can be added to existing alignment models is the subcultural dimension. Alignment models, which have mostly considered strategic, structural, and informal alignments in IS research, may provide further insights into the alignment process by incorporating "subcultural alignment" as an important type of alignment. Future research is needed to explore the nature and stability of such subcultural alignments within the different subcultures and also to examine the longerterm implications of differences in alignment for the same system across units.
A second theoretical implication of our study concerns the intersection of alignment and implementation. Our case illustrates that organizations confront challenges of alignment and implementation simultaneously rather than sequentially, as is often assumed in guidelines for alignment and implementation. Implementation research largely assumes that systems must be aligned strategically prior to implementation for implementation to be successful. Likewise, alignment research assumes that successful implementation helps ensure that a system is aligned and can deliver on its intended goals (Reich and Benbasat 2000). Our case helps illustrate the intertwined nature of alignment and implementation in organizationwide systems.

IS research, drawing on different "modes of control" in organizations offers further illustration of the integration of the alignment and implementation in organization-wide IS (e.g., Henderson and Lee 1992; Kirsch 1996, 1997, 2004). Based on studies of control in organizations (e.g., Jaworski 1988, Ouchi 1978), this research stream has highlighted the formal and informal control mechanisms deployed in organizations to align the goals of different stakeholders during IS development projects. For instance, based on four case studies of IS development projects, Kirsch (1997) showed that in aligning the interests of multiple stakeholders during the implementation process, organizations put in place formal control mechanisms such as project-related rules and procedures, which controlled employee behavior and helped produce desired outcomes. Additionally, informal control mechanisms, such as common cultural beliefs among user groups and self-managed individuals also assisted the implementation process. More recently, Kirsch (2004) also demonstrated how IS and business stakeholders, to align their goals and interests with an organization-wide IS, adopted a combination of formal and informal control mechanisms.

Similar to how such control mechanisms bridge the intersection of alignment and implementation, our study shows how subcultures bridge the alignment and implementation processes together. Specifically, we built a subculture model of subunit-level alignment, explaining the intersection of alignment and implementation in the context of three different subcultures. Although our study posits that organizational alignment does not ensure subunit level alignment, our results do not suggest that alignment across multiple subcultures is not possible, only that the process of obtaining alignment might differ.

Theoretically, considering our study in the light of the "control" literature, we note that a range of formal and informal control mechanisms may facilitate 


\section{Figure 4 A Summary of the KMS Implementation and Issues of Alignment}

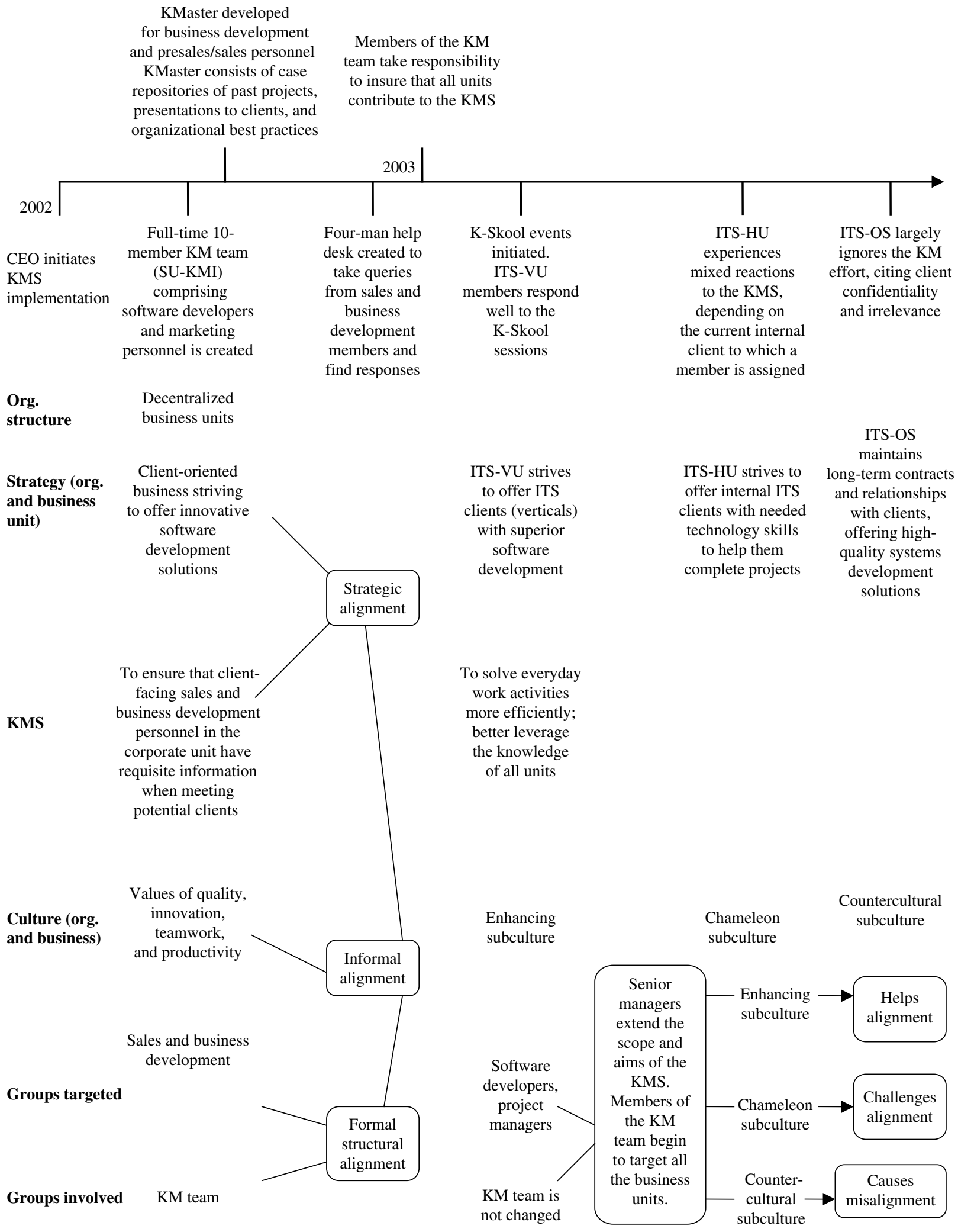


subcultural alignment in different subunits. Indeed, this point finds resonance in the subculture model developed earlier. For instance, from a "control" point of view, the top-bottom-up approach suggested to help implementation success in a chameleon subunit may effectively be operationalized via a combination of formal and informal control mechanisms. Future research needs to delve into the control mechanisms that are most effective within each subculture. Equally, it is also important to examine the extent of influence of subcultures on the formal and informal modes of control existing in an organization. In other words, considering the "control" literature in the light of our study, we suggest that future research can examine how different subcultures impact the control mechanisms used to foster alignment in the case of IS implementations.

The intersection of alignment and implementation highlighted in our study also suggests that research into the dynamic perspective of alignment may need to factor in implementation challenges at the subunit level to better understand the factors underpinning transitory phases of high and low alignments. Research on IS implementation, on the other hand, may explain implementation success better by examining patterns of subunit alignment in organizations.

Our third theoretical implication concerns research in culture and IS. In their review of culture and IS research, Leidner and Kayworth (2006) found only scant attention to subculture. In fact, only five of the studies empirically addressed the issue of subculture and its importance to IS (Dubé and Robey 1999, El Sawy 1985, Huang et al. 2003, Robbins 2000, Von Meier 1999). Of these, some examine the influence of occupational subcultures on technology innovation and diffusion (Von Meier 1999, Robbins 2000) or on intraorganizational collaboration and information sharing (Huang et al. 2003). Others use a broader categorization of subculture-such as Martin's (1992) integration, differentiation, and fragmentation perspective-to better understand software development management practices (Dubé and Robey 1999) or Martin and Siehl's (1983) enhancing, orthogonal, and countercultural subculture types to better understand IT implementation (El Sawy 1985). Our study contributes to the work on culture and IS by considering the alignment problem through a subculture lens. Although larger cultural issues at the national and organizational level might well exert influence on alignment, our study chose to look at different subcultures within the same national and organizational cultural context. In so doing, we gained a better understanding into the role of subculture. Future research should examine the relationships between organizational-level culture and alignment, as well as consider the possibility that IS alignment processes might vary across national cultures.

\section{Concluding Remarks}

Although our study is based on a single case, we wish to draw attention to its adoption of the principles of "analytical generalizability" (Yin 2003) or what Lee and Baskerville (2003, p. 236) refer to as the process of "generalizing from empirical statements to theoretical statements." Nonetheless, our study is not without its limitations. First, we focused entirely on internal opinions and did not seek the opinions of clients of ITS, which might provide a different perspective of ITS' culture. Second, a part of the explanation for the different responses to the KMS, particularly for the overwhelming acceptance in ITS-VU, could also lie in the conforming values and norms of the national culture of India (Hofstede 1961). However, given our focus on subcultures, we did not consider the broader dimensions of national cultures in our study. However, we note that the national culture is consistent across subunits, and yet the subcultures exhibited marked variety. Last, a part of our data collection (particularly the data corresponding to the corporate unit) was retrospective and this may have influenced our analysis.

In conclusion, subcultures bring into sharp focus the socially constructed dimensions of alignment influencing both the perception of and response to the implementation of an organization-wide system. In our study, we used Martin and Siehl's (1983) conceptualization of three subcultures because it is effective in comparing a subunit's culture to that of the broader organization. Our findings suggest that a fourth subculture might be in order, that culture of internally itinerant knowledge workers who neither identify strongly with the organization nor with their structural unit, but adapt the norms and values of the subunit to which they are temporarily assigned. We labeled this a chameleon culture.

In arguing for adopting a process-based practice lens to IS research, Orlikowski (1996, p. 63) drew attention to how "a practice lens can avoid the strong assumptions of rationality, determinism, or discontinuity characterizing existing change perspectives." Although the IS alignment research, when taking a dynamic perspective of alignment and highlighting informal structures, has certainly managed to avoid "such strong assumptions," it has been found wanting in handling and articulating at a theoretical level the informal and often less than rational factors emerging from studies. In this context, our study has empirically shown that where less rational but highly influential informal elements play a role, the theoretical framing of subcultures provides a useful analytical tool to explain strategic alignment and implementation success of an IS. 


\section{Appendix A. Data Analysis: Themes and Subcultural Categories}

\begin{tabular}{|c|c|c|c|c|c|c|}
\hline Level & Theme 1 & Theme 2 & Theme 3 & Theme 4 & $\begin{array}{l}\text { Abstracted } \\
\text { theme }^{\mathrm{a}}\end{array}$ & $\begin{array}{l}\text { Cultural/ } \\
\text { subcultural } \\
\text { category }\end{array}$ \\
\hline ITS & $\begin{array}{l}\text { A wise } \\
\text { top management } \\
\text { team }\end{array}$ & $\begin{array}{l}\text { Strong belief in the } \\
\text { importance of } \\
\text { cooperation } \\
\text { between all the } \\
\text { business units }\end{array}$ & $\begin{array}{l}\text { Determination to } \\
\text { implement } \\
\text { IT-based } \\
\text { quality } \\
\text { processes }\end{array}$ & $\begin{array}{l}\text { Information and } \\
\text { communication } \\
\text { openness }\end{array}$ & & Organizational \\
\hline ITS-VU & $\begin{array}{l}\text { Endorsing all } \\
\text { organization-level } \\
\text { initiatives is } \\
\text { important }\end{array}$ & $\begin{array}{l}\text { Top management } \\
\text { team knows very } \\
\text { well what is good } \\
\text { for the unit }\end{array}$ & $\begin{array}{l}\text { IT tools should } \\
\text { be fully } \\
\text { leveraged for } \\
\text { knowledge } \\
\text { sharing and } \\
\text { transfer }\end{array}$ & $\begin{array}{l}\text { Strong positive } \\
\text { identification } \\
\text { with the } \\
\text { top management } \\
\text { team }\end{array}$ & $\begin{array}{l}\text { Supporting } \\
\text { unit }\end{array}$ & Enhancing \\
\hline ITS-OS & Culturally unique & $\begin{array}{l}\text { Strong positive } \\
\text { identification } \\
\text { with the client } \\
\text { organization }\end{array}$ & $\begin{array}{l}\text { Top management } \\
\text { team regularly } \\
\text { interferes }\end{array}$ & $\begin{array}{l}\text { Opposition to } \\
\text { quality-related } \\
\text { best-practice } \\
\text { initiatives }\end{array}$ & $\begin{array}{l}\text { Opposing } \\
\text { unit }\end{array}$ & Countercultural \\
\hline ITS-HU & $\begin{array}{l}\text { Circumstances } \\
\text { dictate actions }\end{array}$ & $\begin{array}{l}\text { Adjusting to the } \\
\text { assigned business } \\
\text { unit is really } \\
\text { important }\end{array}$ & $\begin{array}{l}\text { Need to be } \\
\text { flexible }\end{array}$ & $\begin{array}{l}\text { Offer support to } \\
\text { the dominant } \\
\text { thinking in the } \\
\text { current business } \\
\text { unit }\end{array}$ & $\begin{array}{l}\text { Adapting } \\
\text { unit }\end{array}$ & Chameleon \\
\hline
\end{tabular}

Note. The terms "Themes" and "Cultural/subcultural category" used here can be thought of as similar to Van Maanen's (1983) "first-order concepts" and "second-order concepts."

${ }^{a}$ We did not create an abstracted theme for the overall organizational culture, given our focus on subcultures.

\section{Appendix B. Data Analysis: Themes at the Organization Level}

\begin{tabular}{|c|c|c|}
\hline ITS characteristics & $\begin{array}{l}\text { Percent informants } \\
\text { who mentioned and } \\
\text { discussed the theme }\end{array}$ & Representative quotes \\
\hline Theme 1: A wise top management team & 95.23 & $\begin{array}{l}\text { "They are very knowledgeable and know whats } \\
\text { best for the company" } \\
\text { "Its not just the experience. I think it's the wisdom } \\
\text { that comes with being in the industry for a long } \\
\text { long time" }\end{array}$ \\
\hline $\begin{array}{l}\text { Theme 2: Strong belief in the importance } \\
\text { of cooperation between all the business } \\
\text { units }\end{array}$ & 92.85 & $\begin{array}{l}\text { "Everyone knows what is happening around here" } \\
\text { "We are a very transparent set-up" }\end{array}$ \\
\hline $\begin{array}{l}\text { Theme 3: Determination to implement IT- } \\
\text { based quality processes }\end{array}$ & 85.71 & $\begin{array}{l}\text { "It is absolutely vital that business units talk to each } \\
\text { other if we have to move up the value chain" } \\
\text { "This is our mantra: No unit should live in a bubble" }\end{array}$ \\
\hline $\begin{array}{l}\text { Theme 4: Information and communication } \\
\text { openness }\end{array}$ & 83.33 & $\begin{array}{l}\text { "We constantly scan the environment for best prac- } \\
\text { tices and strive to implement them internally." } \\
\text { "Given what we do and given our steadfast belief } \\
\text { in the power of IT, we will always push through } \\
\text { IT initiatives that help us do better things" }\end{array}$ \\
\hline
\end{tabular}




\section{Appendix C. Data Analysis: Open-Coded Themes Corresponding to ITS-VU}

\begin{tabular}{ll}
\hline ITS-VU characteristics & Representative quotes
\end{tabular}

Theme 1: Endorsing all organization-level initiatives is important

Theme 2: Top management team knows very well what is good for the unit

Theme 3: IT tools should be fully leveraged for knowledge sharing and transfer

Theme 4: Strong positive identification with the top management team
"We need to show our support each and every time"

"Even if it is from a personal career point of view, I think we need to show a great deal of enthusiasm"

"They have been in the game so long and they have our interest at heart"

"Their actions always make sense in the long run"

"With the kind of IT-skills you can find around here, it would be madness not to exploit its potential fully"

"IT, IT, IT. This is the key for internal collaboration"

"We all look-up to them"

"I'd want to be like the CEO. I mean, that's my aspiration"

\section{Appendix D. Data Analysis: Open-Coded Themes Corresponding to ITS-OS}

ITS-OS characteristics

Theme 1: Culturally unique

Theme 2: Strong positive identification with the client organization

Theme 3: Top management team regularly interferes

Theme 4: Opposition to quality-related best-practice initiatives
Representative quotes

"You must understand that the culture here is very special"

"They think they are unique in many ways and when they are dealing with others in the company, this thinking has definitely affected their actions"

"It is true. I am emotionally much closer to my client"

"Sometimes I wonder if they even realize that ITS pays their salaries and not their client"

"Every now and then someone at the top comes with a bright idea to interfere!"

"Why do they always want to know whats going on here?"

"They keeping pushing these unnecessary initiatives down our throat"

"The first instinct here is to say 'no'"

\section{Appendix E. Data Analysis: Open-Coded Themes Corresponding to ITS-HU}

\begin{tabular}{|c|c|}
\hline ITS-HU characteristics & Representative quotes \\
\hline Theme 1: Circumstances dictate actions & $\begin{array}{l}\text { "It all depends really" } \\
\text { "Which business unit I am in determines many things, if you } \\
\text { ask me" }\end{array}$ \\
\hline $\begin{array}{l}\text { Theme 2: Adjusting to the assigned business unit is } \\
\text { really important }\end{array}$ & $\begin{array}{l}\text { "We have to make adjustments and fit in" } \\
\text { "For everybody's sake we need to settle down quickly and } \\
\text { adjust to the business unit's ways of working" }\end{array}$ \\
\hline Theme 3: Need to be flexible & $\begin{array}{l}\text { "Being very rigid is a strict no-no" } \\
\text { "I may have followed a completely different coding process } \\
\text { in my last project, but I simply cannot harp on it now" }\end{array}$ \\
\hline $\begin{array}{l}\text { Theme 4: Offer support to the dominant thinking in } \\
\text { the current business unit }\end{array}$ & $\begin{array}{l}\text { "Many of the business units we work in have their own } \\
\text { norms and practices and for the time we are there, we } \\
\text { religiously follow all of them" } \\
\text { "In my current business unit, everybody is dead serious } \\
\text { about quality processes and now I find myself totally in } \\
\text { agreement with them" }\end{array}$ \\
\hline
\end{tabular}




\section{References}

Agarwal, R., E. Karahanna. 2000. Time flies when you are having fun: Cognitive absorption and beliefs about information technology. MIS Quart. 24(4) 665-694.

Alvesson, M. 1987. Organizations, culture, and ideology. Internat. Stud. Management Organ. 17(3) 4-18.

Avison, D., J. Jones, P. Powell, D. Wilson. 2004. Using and validating the strategic alignment model. J. Strategic Inform. Systems 13(3) 223-246.

Barley, S. R. 1986. Technology as an occasion for structuring: Evidence from observation of CT scanners and the social order of radiology departments. Admin. Sci. Quart. 31(1) 78-108.

Baroudi, J. J., M. H. Olsen, B. Ives. 1986. An empirical study of the impact of user involvement on system usage and information satisfaction. Comm. ACM 29(3) 232-238.

Beer, M., S. C. Voelpel, M. Liebold, E. B. Tekie. 2005. Strategic alignment as organizational learning: Developing fit and alignment through a disciplined process. Long Range Planning 38(5) $445-465$.

Bloor, G., P. Dawson. 1994. Understanding professional culture in organizational context. Organ. Stud. 15(2) 275-295.

Brown, C. V., S. L. Magill. 1994. Alignment of the IS functions with the enterprise. MIS Quart. 18(4) 371-403.

Cegielski, C. G., B. J. Reithel, C. M. Rebman. 2005. Emerging information technologies: Developing a timely IT strategy. Comm. ACM 48(8) 113-117.

Chan, Y. E. 2002. Why haven't we mastered alignment? The importance of the informal organizational structure. MIS Quart. Executive 1(2) 97-112.

Chan, Y. E., S. L. Huff, D. G. Copeland. 1997a. Assessing realized information systems strategy. J. Strategic Inform. Systems 6(4) 273-298.

Chan, Y. E., S. L. Huff, D. W. Barclay, D. G. Copeland. 1997b. Business strategic orientation, information systems strategic orientation, and strategic alignment. Inform. Systems Res. 8(2) $125-150$.

Choe, J.-M. 2003. The effect of environmental uncertainty and strategic applications of IS on a firm's performance. Inform. Management 40(4) 257-268.

Ciborra, B. U. 1992. From thinking to tinkering: The grassroots of strategic information systems. Inform. Soc. 8(4) 297-309.

Cragg, P., M. King, H. Hussin. 2002. IT alignment and firm performance in small manufacturing firms. J. Strategic Inform. Systems 11(2) 109-132.

DeLong, D. W., L. Fahey. 2000. Diagnosing cultural barriers to knowledge management. Acad. Management Executive 14(4) 113-127.

Dubé, L., D. Robey. 1999. Software stories: Three cultural perspectives on the organizational context of software development practices. Accounting Management Inform. Tech. 9(4) 223-259.

Ein-Dor, P., E. Segev. 1982. Organizational computing and MIS structure: Some empirical evidence. MIS Quart. 6(3) 55-68.

El Sawy, O. 1985. Implementation by cultural infusion: An approach for managing the introduction of information technology in organizations. MIS Quart. 9(2) 131-140.

Ghoshal, S., L. Gratton. 2002. Integrating the enterprise. Sloan Management Rev. 44(1) 31-40.

Henderson, J. C., S. Lee. 1992. Managing I/S design teams: A control theories perspective. Management Sci. 38(6) 757-777.

Henderson, J. C., N. Venkatraman. 1993. Strategic alignment: Leveraging information technology for transforming organizations. IBM Systems J. 32(1) 4-16.

Hirschheim, R., R. Sabherwal. 2001. Detours in the path toward strategic information systems alignment. California Management Rev. 44(1) 87-107.
Hofstede, G. 1961. Cultures and Organizations: Software of the Mind. McGraw-Hill, London.

Huang, J. C., S. Newell, R. Galliers, S. L. Pan. 2003. Dangerous liaisons? Component-based development and organizational subcultures. IEEE Trans. Engrg. Management 50(1) 89-99.

Jaworski, B. J. 1988. Toward a theory of marketing control: Environmental context, control types, and consequences. J. Marketing 52(3) 23-39.

Johnson, G. 1992. Managing strategic change-strategy, culture and action. Long Range Planning 25(1) 28-36.

Jordan, E., B. Tricker. 1995. Information strategy: Alignment with organization structure. J. Strategic Inform. Systems 4(4) 357-382.

Kearns, G. S., A. L. Lederer. 2004. The impact of industry contextual factors on IT focus and the use of IT for competitive advantage. Inform. Management 41(7) 899-919.

Kirsch, L. 1996. The management of complex tasks in organizations: Controlling the systems development process. Organ. Sci. 7(1) $1-21$.

Kirsch, L. 1997. Portfolios of control modes and IS project management. Inform. Systems Res. 8(3) 215-239.

Kirsch, L. 2004. Deploying common systems globally: The dynamics of control. Inform. Systems Res. 15(4) 374-395.

Lapointe, L., S. Rivard. 2005. A multilevel model of resistance to information technology implementation. MIS Quart. 29(3) 461-491.

Lapointe, L., S. Rivard. 2007. A triple take on information systems implementation. Organ. Sci. 18(1) 89-107.

Lee, A. S., R. L. Baskerville. 2003. Generalizing generalizability in information systems research. Inform. Systems Res. 14(3) 221-243.

Leidner, D. E., T. Kayworth. 2006. A review of culture in information systems research: Toward a theory of information technology culture conflict. MIS Quart. 30(2) 357-399.

Luftman, J., T. Brier. 1999. Achieving and sustaining business-IT alignment. California Management Rev. 42(1) 109-122.

Luftman, J., R. Kempaiah, B. Nash. 2006. Key issues for IT executives. MIS Quart. Executive 5(2) 81-99.

Madill, A., A. Jordan, C. Shirley. 2000. Objectivity and reliability in qualitative analysis: Realist, contextualist and radical constructionist epistemologies. British J. Psych. 91(1) 1-20.

Markus, M. L. 1983. Power, politics, and MIS implementation. Comm. ACM 26(6) 430-444.

Martin, J. 1992. Cultures in Organizations: Three Perspectives. Oxford, New York

Martin, J., C. Siehl. 1983. Organizational culture and counter culture: An uneasy symbiosis. Organ. Dynam. 12(2) 52-64.

Martinko, M. J., J. W. Henry, R. W. Zmud. 1996. An attributional explanation of individual resistance to the introduction of information technologies in the workplace. Behavioral Inform. Tech. 15(5) 313-330.

Miller, D. 1992. Environmental fit versus internal fit. Organ. Sci. 3(2) 159-178.

Mitrophanous, E. 1997. Soft positivism. Oxford J. Legal Stud. 17(4) 621-641.

Nadler, D., M. Tushman. 1980. A congruence model for diagnosing organizational behavior. Resource Book in Macro Organizational Behavior. GoodYear, Santa Clara, CA, 30-49.

Orlikowski, W. J. 1993. CASE tools as organizational change: Investigating incremental and radical changes in systems development. MIS Quart. 17(3) 309-340.

Orlikowski, W. J. 1996. Improvising organizational transformation over time: A situated change perspective. Inform. Systems Res. 7(1) 63-92.

Ouchi, W. G. 1978. The transmission of control through organizational hierarchy. Acad. Management J. 21(2) 173-192. 
Pan, S. L., D. E. Leidner. 2003. Bridging communities of practice with information technology in pursuit of global knowledge sharing. J. Strategic Inform. Systems 12(1) 71-88.

Pan, S. L., H. Scarbrough. 1999. Knowledge management in practice: An exploratory case study of Buckman Labs. Tech. Anal. Strategic Management 11(3) 359-374.

Peppard, J., J. Ward. 2004. Beyond strategic information systems: Towards an IS capability. J. Strategic Inform. Systems 13(2) 167-194.

Reich, B. H., I. Benbasat. 1996. Measuring the linkage between business and information technology objectives. MIS Quart. 20(1) $55-81$.

Reich, B. H., I. Benbasat. 2000. Factors that influence the social dimension of alignment between business and information technology objectives. MIS Quart. 24(1) 81-114.

Robbins, N. 2000. Technology subcultures and indicators associated with high-technology performance in schools. J. Res. Comput. Ed. 33(2) 111-124.

Robey, D., A. Azevedo. 1994. Cultural analysis of the organizational consequences of information technology. Accounting Management Inform. Tech. 4(1) 23-27.

Robey, D., M. Boudreau. 1999. Accounting for the contradictory consequences of information technology: Theoretical directions and methodological implications. Inform. Systems Res. 10(2) 167-185.

Rockart, J., M. Earl, J. Ross. 1996. Eight imperatives for the new IT organization. Sloan Management Rev. 38(1) 43-55.

Rondinelli, D., B. Rosen, I. Drori. 2001. The struggle for strategic alignment in multinational corporations: Managing readjustment during global expansion. Eur. Management J. 19(4) 404-416.

Sabherwal, R., Y. E. Chan. 2001. Alignment between business and IS strategies: A study of prospectors, analyzers and defenders. Inform. Systems Res. 12(1) 11-33.

Sabherwal, R., P. Kirs. 1994. The alignment between organizational critical success factors and information technology capability in academic institutions. Decision Sci. 25(2) 301-325.
Sabherwal, R., R. Hirschheim, T. Goles. 2001. The dynamics of alignment: Insights from a punctuated equilibrium model. Organ. Sci. 12(2) 179-197.

Schultze, U., W. J. Orlikowski. 2004. A practice perspective on technology-mediated network relations: The use of Internetbased self-serve technologies. Inform. Systems Res. 15(1) 87-106.

Soh, C., S. K. Sia. 2005. The challenges of implementing "vanilla" versions of enterprise systems. MIS Quart. Executive 4(3) 373-384.

Tavakolian, H. 1989. Linking the information technology structure with organizational competitive strategy: A survey. MIS Quart. 13(3) 309-317.

Tyre, M. J., W. J. Orlikowski. 1994. Windows of opportunity: Temporal patterns of technological adaptation in organizations. Organ. Sci. 5(1) 98-118.

Van Maanen, J. 1983. The Fact of Fiction in Organizational Ethnography. J. Van Maanen, ed. Sage Publications, Beverly Hills, CA.

Van Maanen, J., S. R. Barley. 1984. Occupational communities: Culture and control in organizations. L. L. Cummings, B. M. Staw, eds. Research in Organizational Behaviour, Vol. 6. JAI Press, Greenwich, CT, 287-365.

Venkatraman, N., J. C. Henderson, S. Oldach. 1993. Continuous strategic alignment: Exploiting information technology capabilities for competitive success. Eur. Management J. 11(2) 139-149.

Von Meier, A. 1999. Occupational cultures as a challenge to technological innovation. IEEE Trans. Engrg. Management 46(1) 101-114.

Wijnhoven, F., T. Spil, R. Stegwee, R. T. A. Fa. 2006. Post-merger IT integration strategies. J. Strategic Inform. Systems 15(1) 5-28.

Yin, R. K. 2003. Case Study Research, Design and Methods, 3rd ed. Sage Publications, Newbury Park, CA.

Young, E. 1989. On the naming of the rose: Interests and multiple meanings as elements of organizational culture. Organ. Stud. 10(2) 187-206. 